RESEARCH REPORT

\title{
Multilevel modelling of built environment characteristics related to neighbourhood walking activity in older adults
}

\author{
Fuzhong Li, K John Fisher, Ross C Brownson, Mark Bosworth
}

J Epidemiol Community Health 2005;59:558-564. doi: 10.1136/jech.2004.028399

See end of article for authors' affiliations

Correspondence to:

Dr F Li, Oregon Research Institute, 1715 Franklin Boulevard, Eugene, OR 97403, USA

fuzhongl@ori.org

Accepted for publication 17 December 2004

\begin{abstract}
Objective: To examine the relation between built environment factors (representing several dimensions of urban form of neighbourhoods) and walking activity at both the neighbourhood level and the resident level, in an older adult sample.

Design, setting, participants: A cross sectional, multilevel design with neighbourhoods as the primary sampling unit and senior residents as the secondary unit. Five hundred and seventy seven residents (mean age $=74$ years, $S D=6.3$ years) participated in the survey, which was conducted among 56 city defined neighbourhoods in Portland, Oregon, USA. Neighbourhood level variables were constructed using geographical information systems. Resident level variables consisted of a mix of self reports and geocoded data on the built environment.

Main outcome measure: Self reported neighbourhood walking.

Main results: A positive relation was found between built environment factors (density of places of employment, household density, green and open spaces for recreation, number of street intersections) and walking activity at the neighbourhood level. At the resident level, perceptions of safety for walking and number of nearby recreational facilities were positively related to high levels of walking activity. A significant interaction was observed between number of street intersections and perceptions of safety from traffic.

Conclusions: Certain neighbourhood built environment characteristics related to urban form were positively associated with walking activity in the neighbourhoods of senior residents. Public health promotion of walking activity/urban mobility and the design of interventions need to consider the contribution of neighbourhood level built environment influences.
\end{abstract}

cial density), ${ }^{15-20}$ on walking activity using a hierarchical data structure (that is, neighbourhoods, with residents within neighbourhoods). Within a multilevel model framework, we developed neighbourhood level geographical information systems (GIS) measures of urban form characteristics, and resident level measures containing a mix of perceived (that is, self reported) and GIS measures of the built environment. We linked these level specific variables to the outcome variable of walking activity reported by senior residents sampled from a north west city in the USA.

On the basis of current research in physical activity, and transportation planning and public health, ${ }^{21-30}$ we postulated that level specific built environment factors specified in this study would independently account for variation in older adults' walking both at the neighbourhood level and at the resident level. Our specific hypothesis was that neighbourhoods with high level density of places of employment, high level household density, greater numbers of street intersections, and green and open spaces for recreation, would be positively associated with increased walking activity in neighbourhoods. We also explored the hypothesis that resident level GIS measures would interact with self reported measures of neighbourhood environment to jointly influence walking activity at the resident level. These hypotheses were examined using data from a community physical activity survey of older adults.

\section{METHODS}

\section{Study area and population}

The study geographical area covered all city defined neighbourhoods in Portland, Oregon. Portland is Oregon's largest city, with an estimated population of 529121 people, according to the 2000 census. The population was primarily factors, representing dimensions of urban form of neighbourhoods (that is, accessibility, proximity, residential/commer- 


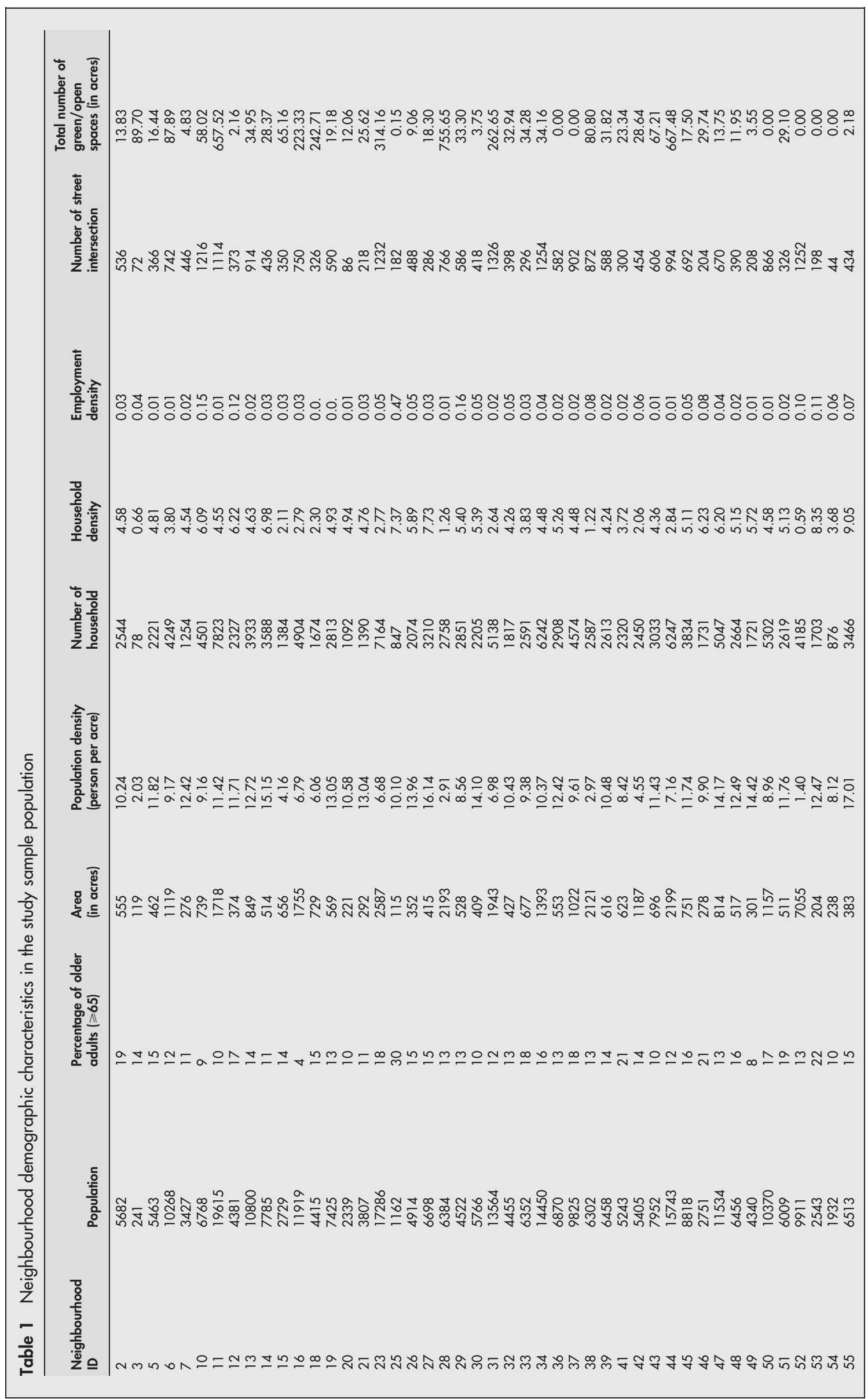




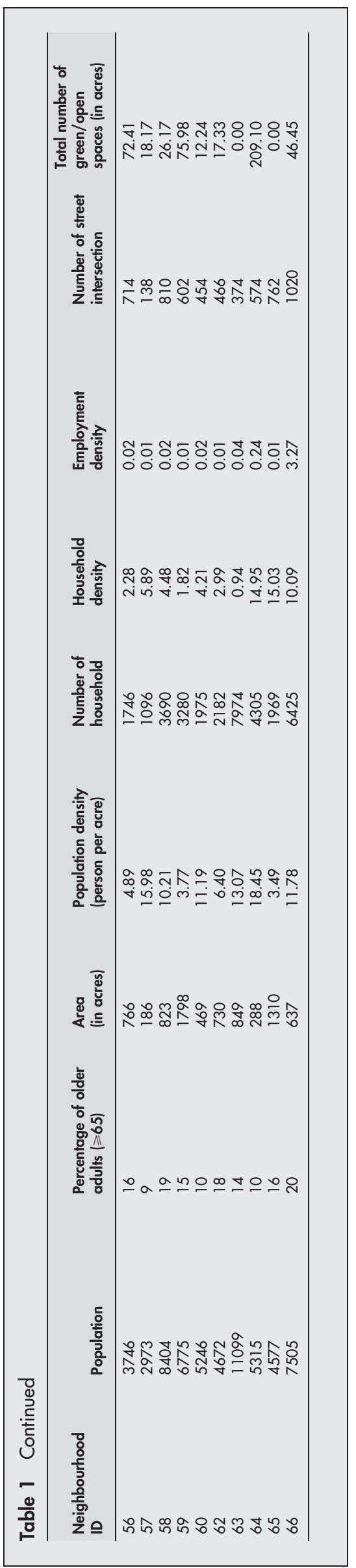

white (78\%), with African Americans accounting for $6.6 \%$ of the population. Median household income was $\$ 40146$, with $29.9 \%$ of households having an income under $\$ 25000$. About $11.6 \%$ of this population was 65 years old and over, and $10.4 \%$ of senior residents was below the poverty level.

\section{Study design}

This study used a cross sectional, cluster, multistage sampling design in which neighbourhoods were first pre-selected (stage 1), followed by recruitment of individual residents from each neighbourhood (stage 2), who were surveyed with respect to levels of neighbourhood walking activity. This two stage sampling scheme resulted in a two level data structure (that is, neighbourhoods, residents within neighbourhoods), with neighbourhoods corresponding to the primary sampling unit, and residents within each primary sampling unit to the secondary unit. Details are presented below.

\section{Study sample units}

At the time of the study (2001), there were 93 city defined neighbourhoods in the city of Portland, Oregon. Fifteen neighbourhoods were removed from the initial sampling pool because of low population density, commercial, and nonresidential areas, leaving 78 neighbourhoods in the final pool. To obtain a higher representation of low income and high minority neighbourhoods, we oversampled $20 \%$ of neighbourhoods with households below the poverty level. This resulted in 56 neighbourhoods as the final sample size for the study. The sampled neighbourhoods varied in area (ranging from 32 to 7055 acres; median = 537), and so did the numbers of elderly residents per neighbourhood (ranging from 42 to 3351; median $=689$ ). Table 1 presents neighbourhood demographic and built environment characteristics relevant to this study.

After the 56 neighbourhoods were sampled, individual residents, aged 65 years of age or older, within each of the 56 neighbourhoods were recruited through computer assisted telephone interview procedures and direct mail to participate in a neighbourhood based walking programme. ${ }^{31}$ From 2181 people who were initially contacted and screened for eligibility, 582 residents qualified per study criteria and completed the study survey, representing a $31 \%$ response rate. The within neighbourhood sample size in this study ranged from 3 to 17 residents with a mean of 10 .

\section{GIS mapping}

ArcGIS software (ArcInfo, version 9, Redlands, CA, Environmental Systems Research Institute) was used for data acquisition and development, and subsequent spatial analysis. This study used the existing geographical databases provided by the regional land information system (RLIS). RLIS includes a complete and current street address database as well as many other data layers from which the characteristics of urban form and neighbourhood demographic and built environment characteristics relevant to this study were derived.

Before calculating GIS built environment variables, all residents in the study were address geocoded. The results of this geocoding process created a spatial coordinate $(\mathrm{x}, \mathrm{y}$ pairs in the Stateplane coordinate system) for each resident's home allowing for further analysis of these locations in relation to other GIS layers. A total of 577 of 582 study respondents were successfully address matched, an accuracy level of 99\%. Data for five residents were excluded (three provided a post office box and two residents (a couple) provided an out of state mailing address). Figure 1 displays the map showing the geocoded 577 study residents' locations across the 56 study neighbourhoods.

Characteristics of the study participants are summarised in a previously published work. $^{24}$ Briefly, participants' ages 


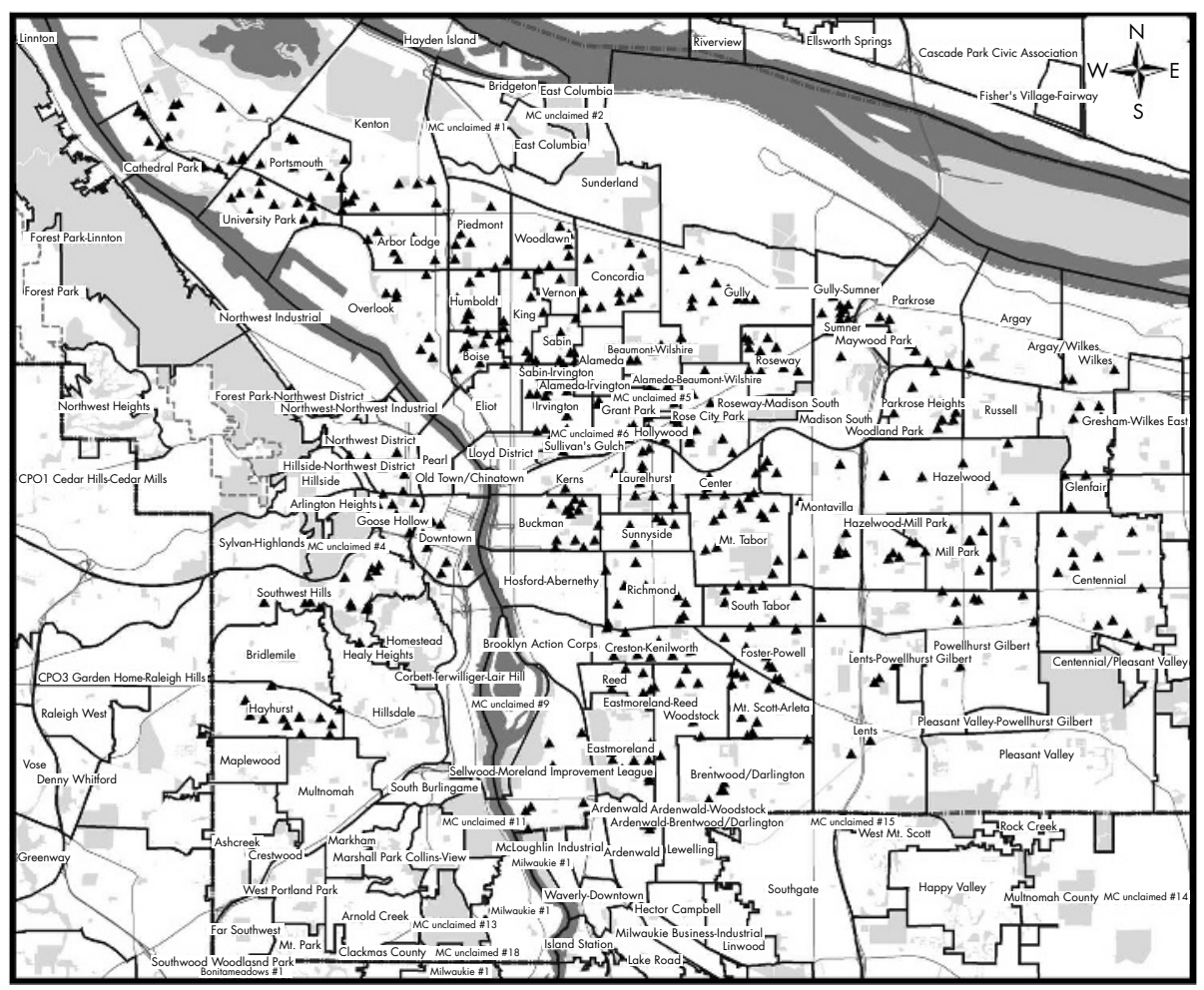

Figure 1 Map of geocoded participants' residences across 56 study neighbourhoods in Portland, Oregon.

ranged from 65 to 94 years (mean age $=74$ years, $S D=6.3$ years). Most participants were women (64\%), married (49\%), white $(92 \%)$, had a high school degree or higher $(88 \%)$, and had a household income of $\$ 29999$ or below (65\%). The mean value for health status (measured on a five point Likert scale: $1=$ very poor, $5=$ excellent $)$ was $3.33(\mathrm{SD}=0.96)$.

\section{Study measures}

Residents completed a questionnaire that collected age, sex, marital status, education, household income, and health status. Details on the study's dependent and independent measures are described below.

\section{Outcome variable: neighbourhood walking}

Neighbourhood walking was defined as engaging in three types of activities (for example, walking, strolling, other physical activities) that were conducted in the respondents' neighbourhood..$^{24}$ For each activity, participants rated their responses on a five point Likert scale ranging from 1 (not at all) to 5 (a great deal). Scores for these three items were averaged to obtain a single walking activity score, with higher scores representing high levels of walking activity. Internal consistency (Cronbach $\alpha$ ) for this scale was 0.70 . The scale was also shown to have adequate test-retest reliability $(r=0.61)$ and construct validity. ${ }^{24}$

\section{Neighbourhood level variables}

ArcGIS was used to develop four built environment measures per neighbourhood: (1) number of residential households, (2) number of places of employment (for example, offices and commercial buildings, workplaces, etc), (3) number of street intersections including those with traffic lights and those without (excluding freeway ramps), and (4) total green and open spaces for recreation, including public parks, open areas for recreation such as playgrounds (in acres). Based on these measures, variables for density of places of employment and density of households were created by dividing the number of places of employment and resident households in

Table 2 Parameter estimates (unstandardised $\beta$ weights) derived from the multilevel model

\begin{tabular}{|c|c|c|c|c|}
\hline Neighbourhood level & $\begin{array}{l}\text { Path coefficient } \\
(95 \% \mathrm{CI})\end{array}$ & $\begin{array}{l}\text { Standard } \\
\text { error }\end{array}$ & $t$ Value & p Value \\
\hline Employment density $\rightarrow$ neighbourhood walking & $0.187(0.061$ to 0.313$)$ & 0.06 & 2.901 & 0.05 \\
\hline Household density $\rightarrow$ neighbourhood walking & $0.047(0.001$ to 0.094$)$ & 0.024 & 1.998 & 0.05 \\
\hline Number of street intersections $\rightarrow$ neighbourhood walking & $0.531(0.236$ to 0.826$)$ & 0.151 & 3.527 & 0.01 \\
\hline $\begin{array}{l}\text { Area of green and open space for recreation } \rightarrow \text { neighbourhood walking } \\
\text { Resident level }\end{array}$ & $0.074(0.009$ to 0.140$)$ & 0.033 & 2.238 & 0.05 \\
\hline Access to recreational facilities $\rightarrow$ neighbourhood walking & $0.022(-0.058$ to 0.102$)$ & 0.041 & 0.542 & 0.22 \\
\hline Safe to walk $\rightarrow$ neighbourhood walking & $0.148(0.055$ to 0.242$)$ & 0.048 & 3.101 & 0.01 \\
\hline Safe from traffic $\rightarrow$ neighbourhood walking & $0.152(-0.016$ to 0.321$)$ & 0.086 & 1.771 & 0.06 \\
\hline Number of recreational facilities $\rightarrow$ neighbourhood walking & $0.077(0.052$ to 0.103$)$ & 0.013 & 5.921 & 0.001 \\
\hline Number of street intersections $\rightarrow$ neighbourhood walking & $0.010(-0.117$ to 0.137$)$ & 0.065 & 0.153 & 0.22 \\
\hline Area of green and open space for recreation $\rightarrow$ neighbourhood walking & $-0.056(-0.103$ to -0.009$)$ & 0.024 & -2.320 & 0.05 \\
\hline Area of green and open spaces by access interaction $\rightarrow$ neighbourhood walking & $-0.022(-0.060$ to 0.016$)$ & 0.019 & -1.121 & 0.13 \\
\hline $\begin{array}{l}\text { Number of street intersections by safe from traffic interaction } \\
\rightarrow \text { neighbourhood walking }\end{array}$ & 0.019 (0.007 to 0.032$)$ & 0.006 & 2.977 & 0.05 \\
\hline
\end{tabular}


each neighbourhood by the total number of acres in the neighbourhood.

\section{Resident level variables}

Using the same GIS procedures described previously, resident level GIS measures were constructed by calculating corresponding measures of (1) number of street intersections, and (2) total area of green and open spaces for recreation, within 0.5 mile radius of each resident's home address. The 0.5 mile radius approximates a 10 minute walk area or "pedestrian shed" and is considered a reasonable distance for assessing the proximity of physical activity facilities. ${ }^{32}$

An additional four variables were constructed based on self reports: (1) proximity to local recreational facilities, (2) safety for walking, (3) safety from traffic, and (4) number of nearby recreational facilities. Each is described below.

Proximity to local physical activity facilities was measured through a single item assessing the extent to which participants agreed or disagreed with the following statement: "There are playgrounds, parks, or gyms, close by that I can get to easily." The scale ranged from 1 (strongly disagree) to 5 (strongly agree), with higher scores representing close proximity to local physical activity facilities. A three month test-retest reliability coefficient of 0.56 was obtained.

Two items were used to measure perceptions of safety for walking in the neighbourhood..$^{33}$ On a scale ranging from 1 (strongly disagree) to 5 (strongly agree), participants were asked to indicate the extent to which they agreed or disagreed with the statements: (1) "It is safe to walk or jog alone in my neighbourhood during the day," and (2) "Unsafe sidewalks (obstacles to walking) are a problem." The second item was reverse coded so that it represented safety for walking. A three month test-retest reliability coefficient of 0.56 was obtained.

A single item measuring safety from traffic was used. Respondents were asked to respond, on a five point Likert scale ( strongly disagree $=1$, strongly agree $=5$ ), how much they agreed that neighbourhood traffic was a problem. The item was recoded so that high scores represented higher levels of safety from traffic. A three month test-retest reliability coefficient of 0.56 was obtained.

A measure reflecting number of recreational facilities in the neighbourhood ${ }^{34}$ was used to form a list of 11 facilities (for example, senior centres, gym/fitness centres, public parks, trails) provided by each resident. A three month testretest reliability coefficient of 0.64 was obtained.

\section{Interaction terms}

It was hypothesised that the extent to which areas of green and open space for recreation accessed by residents in a neighbourhood may depend on their perceptions of its proximity. Similarly, the extent to which residents walk in

\section{What this paper adds}

- Evidence of neighbourhood to neighbourhood variation in walking activity of older adults.

- Neighbourhoods with high level density of places of employment and household density, greater numbers of street intersections, and green and open spaces for recreation, are more likely to engage in walking activity.

- The number of street intersections contributes to walking activity only when residents perceive that traffic conditions related to these intersections near their residence are safe. their neighbourhood streets may depend on their perceptions of traffic safety and busy street intersections. Therefore, to explore the potential of these moderating effects, two interaction terms were constructed. The first interaction (cross product) term was made between proximity to facilities and areas of green and open space for recreation. The second interaction term involved "safe to walk" and "number of street intersections."

\section{Data analysis}

Neighbourhood and resident level data and outcome data were combined into a single database. The resulting data contained a two level structure: residents (level 1), neighbourhoods (level 2), and they were analysed within a multilevel path analysis framework, in which all variables (both exogenous and endogenous) were observed or manifested, and treated as continuous variables. ${ }^{26}$

Neighbourhood effects on walking activity were determined by calculating the intraclass (intra-neighbourhood) correlation (ICC), defined as a ratio of between neighbourhood variability/(between neighbourhood variability + within neighbourhood variability). The size of an ICC, however, depends on the size of the clusters. ${ }^{35}$ Both cluster size and ICC contribute to the design effect, which is about equal to $1+$ (average cluster size -1 ) times ICC. ${ }^{37}$ Both indices are important because they provide justification for the application of a multilevel analysis.

In this multilevel modelling of hierarchical data, both neighbourhoods and residents are the units of analysis, permitting the simultaneous evaluation of between neighbourhood and within neighbourhood variability in the walking activity outcome. The overall analysis goal is to decompose the total variation in the neighbourhood walking activity scores $\left(Y_{\mathrm{T}}\right)$ into a between and a within neighbourhood part: $\Sigma_{\mathrm{T}}=\Sigma_{\mathrm{B}}+\Sigma_{\mathrm{W}}$, where $\Sigma_{\mathrm{B}}$ refers to neighbourhoodlevel variation and $\Sigma_{\mathrm{W}}$ refers to resident level variation in walking activity. This type of multilevel model is referred to as a disaggregated model for multilevel data. ${ }^{34}$ In our multilevel path model, level specific variables were specified at the level of neighbourhoods and at the level of residents. The outcome variable of neighbourhood walking was regressed on all GIS and perceived built environment variables at their respective level in the model. The Mplus, version 3.0 software package (Muthén and Muthén, Los Angeles, CA) was used to analyse the multilevel model. Parameter estimates were generated through maximum likelihood estimation. Both standardised and unstandardised point estimates and their 95\% confidence intervals are presented.

\section{RESULTS}

\section{Results at the neighbourhood level}

Intraclass correlation of the outcome variable of walking was 0.28 , showing that $28 \%$ of the variation in reported walking activity was attributable to between neighbourhood differences. The design effect for the walking activity variable was $3.54(1+[10.39-1] \times 0.28)$. This provided justification for multilevel analysis. Table 2 shows parameter estimates (unstandardised) generated from the multilevel path model estimation.

\section{Policy implications}

Policies to promote physical activity need to consider features of built environments that facilitate older adults' walking activity in their neighbourhood. 
Results showed that density of places of employment in the neighbourhood ( $\beta=0.15$, where $\beta$ indicates the standardised coefficient), household density $(\beta=0.27)$, number of street intersections $(\beta=0.37)$, and area of green and open spaces $(\beta=0.23)$, were all significantly related to walking activity at the neighbourhood level. Twenty two per cent of the variation in neighbourhood level walking was accounted for collectively by these four exogenous neighbourhood level variables.

\section{Results at the resident level}

Parameter estimates (table 2) showed that number of recreational facilities $(\beta=0.22)$ and areas reported by the residents that were safe for walking $(\beta=0.12)$, were significantly related to walking activity. In addition, significant interaction was found between the variables of number of street intersections and perceptions of safety from traffic. Residents in neighbourhoods with more street intersections who reported being safer from traffic tended to report more neighbourhood walking activity. No significant interaction was observed between proximity of physical activity facilities and areas of green and open space $(p=0.26)$. Resident level variables only accounted for $9 \%$ of the within neighbourhood variation in neighbourhood walking scores.

\section{DISCUSSION}

The results from this study showed a significant neighbourhood effect with respect to walking activity in older adults. This effect was manifested by interneighbourhood variations $(28 \%)$ in walking activity, indicating the existence of neighbourhood to neighbourhood variation in older adults' walking activity among the 56 sampled neighbourhoods in this study. Moreover, the study results showed that variation in walking activity across neighbourhoods was accounted for by the selected neighbourhood level built environment characteristics. Findings showed that neighbourhoods with high level density of places of employment, high level household density, greater numbers of street intersections and green and open spaces for recreation, were associated with more frequent walking activity. These results are largely consistent with reports that increased density and mixed land use are related to more walking/cycling. ${ }^{16} 212327-2937-39$ Although direct comparisons between this study and those mentioned previously are not possible because of differences in design, analyses, outcome measures, and age groups, this is nevertheless the first multilevel study, involving a simultaneous analysis of neighbourhoods and residents, that provides support for the notion that density and land use mix (for example, higher population density, greater mixed land use, higher street connectivity) should be considered in planning and promoting community based physical activity, including walking.

At the resident level, results showed that residents' perceptions of proximity to recreational facilities and safety for walking in the neighbourhood were significantly related to neighbourhood walking. These findings are congruent with the current physical activity literature. ${ }^{10} 13$ In addition, the resident level analysis also showed that the "safe from traffic" variable was found to interact with the GIS measure of "number of street intersections" in the neighbourhood. Specifically, perceived safety from traffic in residents' areas containing greater numbers of street intersections (that is, within a half mile radius of their residence) was associated with a greater amount of neighbourhood walking by older adults.

\section{Practical implications}

An important part of understanding neighbourhood effects on physical activity is to show inter-neighbourhood variability in the outcome measures. Toward this end, our data show sufficient evidence of neighbourhood level variation in residents' reports of neighbourhood walking activity. The sizes of the intraclass correlation (28\%) and the design effect, suggest important clustering or neighbourhood effects in relation to neighbourhood walking. Therefore, by considering the clustering (or neighbourhood) effect, researchers can evaluate the relative importance of neighbourhood level effects on targeted health related outcomes. Estimation of neighbourhood effects also has value in the context of ideas about the efficacy of focusing interventions on neighbourhoods instead of individuals, and the need to advocate for more neighbourhood centred resource provision for health related outcomes.

Public health strategies to promote physical activity or walking should emphasise the important role of environmental influences that facilitate opportunities and remove barriers for people to be more active. ${ }^{12}$ In this respect, findings from this study suggest that neighbourhoods containing high employment density and household density, more street intersections, and greater amounts of green and open spaces for recreation, are likely to increase urban mobility and be conducive to "walkable" neighbourhoods. The results also suggest that each of these environmental characteristics contributes independently to neighbourhood walking. In addition, the amount of variance explained by the combination of these neighbourhood level variables also shows their collective contribution in explaining neighbourhood to neighbourhood variation in walking activity.

Important implications arise from the finding on the interaction between residents' feeling safe from traffic, and numbers of street intersections. This finding implies that the number of neighbourhood street intersections would contribute to neighbourhood walking only when residents perceive that the traffic conditions related to these intersections near their residence are safe for walking. Such a description would seem to fit traditional neighbourhoods connected by networks of intersecting streets that are safe from busy traffic.

\section{Study limitations}

This study has a number of limitations. Firstly, the study was restricted to a single geographical area, the city of Portland, well known for its management of urban growth. ${ }^{20}{ }^{40}$ The results, therefore, may only be generalisable to the geographical characteristics that are similar to that region. Secondly, our dependent outcome, walking activity, is based on self reports, and therefore, may be subject to self report bias that does not capture all domains of this activity. ${ }^{41}$ However, self reports in physical activity are common in the field and remain the primary source for assessing walking activity in large scale studies like this. ${ }^{42}$ Thirdly, small within cluster sample sizes (average $=10$ ) limit this study from addressing issues related to variation in the fixed effects observed. Finally, cross sectional data were used to study the relations between environment characteristics and walking behaviours. The full evaluation of causal inferences about neighbourhood effects on physical activity will require longitudinal and multilevel analyses of physical activity over time. ${ }^{12}$ In this regard, a recent multilevel study found preliminary evidence of neighbourhood level of change and predictors in change in walking activity over time among a sample of older adults. ${ }^{43}$

\section{Future research}

Further work is needed to develop a much more comprehensive mix of GIS measures of the physical and built environment (for example, climate, topography, density) that may be related to physical activity in community settings. For example, particular measures, such as busy streets, hilly terrain, need to be developed to examine how they may 
potentially affect physical activity patterns. Future research should also focus on the influences of social, physical, and built environment characteristics on change in walking behaviours at the neighbourhood level. Given the increasing impetus to promote physical activity from several authorities, ${ }^{124-47}$ research is urgently needed to examine changes in physical activity over time at the neighbourhood/community level. ${ }^{43}$ Furthermore, it would be unreasonable to assume that individuals or neighbourhoods, or both, have the same trajectories of change in patterns of physical activity over time. Therefore, there is a need to consider heterogeneity of change in physical activity over time at the individual level as well as at the neighbourhood level. Finally, the issue of cross level interaction has not been considered or addressed in the physical activity and public health literature. ${ }^{12}$ Therefore, future studies need to recognise and identify neighbourhood level and individual level factors that may moderate the strength of association between neighbourhood influences and physical activity and urban mobility at either level, or across levels, or both.

In summary, this study contributes to the paucity of multilevel research on evaluating the influence of neighbourhood built environment factors, particularly those related to urban form, on walking activity in the neighbourhoods of senior residents. Findings from this study suggest that public health promotion of walking, transportation, and urban planning, and the design of intervention programmes need to consider the contribution of neighbourhood level built environment factors to facilitate behaviour change among individuals and communities.

\section{Authors' affiliations}

F Li, K J Fisher, Oregon Research Institute, Eugene, USA

R C Brownson, Department of Community Health and Prevention Research Center, Saint Louis University School of Public Health, USA M Bosworth, Metro Regional Services, Portland, Oregon, USA

Funding: this project was funded by the National Institutes of Health, National Institute on Aging, Grant AG17510, and in part by AG18394.

Conflicts of interest: none declared.

Ethics approval: the Institutional Review Board of Oregon Research Institute approved the research protocol, and all study participants provided informed consent before study surveys were conducted.

\section{REFERENCES}

1 US Department of Health and Human Services. Healthy people 2010: understanding and improving health. Washington, DC: US Department of Health and Human Services, 2000

2 US Department of Health and Human Services. Physical activity and health: a report of the surgeon general. Atlanta, GA: Centers for Disease Control and Prevention, 1996.

3 Eyler AA, Brownson RC, Bacak SJ, et al. The epidemiology of walking for physical activity in the United States. Med Sci Sports Exerc 2003;35:1529-36.

4 Rafferty AP, McGee HB, Petersmarck KA, et al. Proportion of trips made by walking: estimating state-level baseline for Healthy People 2010 Objective 22-14. Am J Health Promotion 2002; 18:387-91.

5 Siegel PR, Brackbill R, Heath G. The epidemiology of walking for exercise: implications for promoting activity among sedentary groups. Am J Public Health 1995;85:706-10.

6 Simpson ME, Serdula M, Galuska DA, et al. Walking trends among US adults: The Behavioral Risk Factor Surveillance system, 1987-2000. Am J Prev Med 2003;25:95-100.

7 Kawachi I, Berkman L. Neighborhoods and health. New York, NY: Oxford University Press, 2003.

8 Shinn M, Toohey SM. Community contexts of human welfare. Annu Rev Psychol 2003;54:427-59.

9 Bauman A, Sallis JF, Owen N. Environmental and policy measurement in physical activity research. In: Welk GJ, ed. Physical activity assessments for health-related research. Champaign, IL: Human Kinetics, 2002:241-51

10 Humpel N, Owen N, Leslie E. Environmental factors associated with adults' participation in physical activity. Am J Prev Med 2002;22:188-99.

11 King AC, Stokols D, Talen E, et al. Theoretical approaches to the promotion of physical activity: forging a transdisciplinary paradigm. Am J Prev Med 2002; 23:15-25.

12 Li F, Fisher KJ, Bauman A, et al. Neighborhood influences on physical activity in older adults: a multilevel perspective. J Aging Phys Act 2005;13:32-58.
13 Owen N, Humpel N, Leslie $\mathrm{E}$, et al. Understanding environmental influences on walking: Review and research agenda. Am J Prev Med 2004;27:67-76.

14 Saelens BE, Sallis JF, Frank LE. Environmental factors that promote walking and cycling: findings from the transportation, urban design and planning literatures. Ann Behav Med 2003;25:80-91.

15 Berman M. The transportation effects of neo-traditional development. Journal of Planning Literature 1996;10:347-63.

16 Frank LD, Pivo G. Impacts of mixed use and density on utilization of three modes of travel: single-occupant vehicle, transit, and walking. Transportation Res Record 1994; 1466:44-52.

17 Handy S. Urban form and pedestrian choices. Transportation Res Record 1996;1552:135-44.

18 Handy S. Understanding the link between urban form and non-work travel behavior. J Planning Educ Res 1996;15:183-98.

19 Handy S, Boarnet MG, Ewing R, et al. How the built environment affects physical activity: views from urban planning. Am J Prev Med 2002;23:64-73.

20 Song Y, Knaap GJ. Measuring urban form: Is Portland winning the war on sprawl? J Am Planning Assoc 2004;70:210-25.

21 Berrigan D, Troiano RP. The association between urban form and physical activity in U.S. adults. Am J Prev Med 2002;23:74-9.

22 Brownson RC, Baker EA, Housemann RA, et al. Environmental and policy determinants of physical activity in the United States. Am J Public Health 2001;91:1995-2003.

23 Ewing R, Schmid T, Killingsworth R, et al. Relationship between urban sprawl and physical activity, obesity, and morbidity. Am J Health Promot 2003;18:47-57.

24 Fisher KJ, Li F, Michael Y, et al. Neighborhood level influences on physical activity among older adults: a multilevel analysis. J Aging Phys Act 2004;11:49-67.

25 Kitamura R, Mokhtarian PL, Laidet L. A micro-analysis of land use and travel in five neighborhoods in the San Francisco Bay Area. Transportation 1997;24:125-58.

26 Li F, Fisher KJ. A multilevel path analysis of the relationship between physical activity and self-rated health in older adults. J Phys Act Health 2004; 1:398-412

27 Parsons Brinckerhoff Quade, Douglas. 1000 Friends: making land use transportation air quality connections - the pedestrian environment. Vol 4A. Portland, OR: 1000 Friends of Oregon, 1993.

28 Parsons Brinckerhoff Quade, Douglas, Building orientation. A supplement to the pedestrian environment. Vol 4B. Portland, OR: 1000 Friends of Oregon, 1994.

29 Ross CL, Dunning AE. Land use transportation interaction: an examination of the 1995 NPTS data. Washington, DC: US Department of Transportation, 1997.

30 Wanda Wendel-Vos GC, Schuit AJ, De Niet R, et al. Factors of the physical environment associated with walking and bicycling. Med Sci Sports Exerc 2004;36:725-30

31 Fisher KJ, Li F. A community-based walking trial to improve neighborhood quality of life in the elderly: a multilevel analysis. Ann Behav Med 2004;28:186-94

32 Calthorpe P. The next American metropolis: ecology, community and the American dream. New York: The Princeton Architectural Press, 1993.

33 Sallis JF, Johnson M, Calfas KJ, et al. Assessing perceived physical environment variables that may influence physical activity. Res Q Exerc Sport 1997;68:345-51

34 Muthén B. Latent growth modeling with longitudinal and multilevel data. In: Raftery $A E$, ed. Sociological methodology. Boston, MA: Blackwell, 1997:453-80.

35 Muthén B, Satorra A. Complex sample data in structural equation modeling. In: Marsden PV, ed. Sociological methodology. Oxford: Blackwell, 1995:267-316

36 Kish L. Survey sampling. New York: Wiley, 1965.

37 Cervero, R. Mixed land-uses and commuting: evidence from the American Housing Survey. Transportation Research-A 1996;30:361-77.

38 Hanson S, Schwab M. Accessibility and intraurban travel. Environment and Planning-A 1987; 19:735-48.

39 Kockelman KM. Travel behavior as function of accessibility, land use mixing, and land use balance: evidence from San Francisco Bay area. Transportation Research Record 1997; 1607:116-25

40 Abbott C. Planning a sustainable city: the promise and performance of Portland's urban growth boundary. In: Squires GD, ed. Urban sprawl: causes, consequences and policy responses. Washington, DC: Urban Institute Press, 2002:207-35.

41 Craig CL, Marshall AL, Sjostrom M, et al. International physical activity questionnaire: 12-country reliability and validity. Med Sci Sports Exerc 2003;35:1381-95.

42 Welk GJ. Physical activity assessments for health-related research Champaign, IL: Human Kinetics, 2002.

43 Li F, Fisher KJ, Brownson RC. A multilevel analysis of change in neighborhood walking activity in older adults. J Aging Phys Act 2005;13:145-59.

44 Chodzko-Zajko WJ. National Blueprint: increasing physical activity among adults age 50 and older. J Aging Phys Act 2001;9:2-18.

45 Robert Wood Johnson Foundation. National blueprint for increasing physical among adults 50 and older: creating a strategic framework and enhancing organizational capacity for change. J Aging Phys Act 2000;9:5-28.

46 Sheppard R, Senior J, Park CH, et al. The National Blueprint consensus conference summary report: strategic priorities for increasing physical activities among adults aged $\geqslant 50$. Am J Prev Med 2003;25:209-13.

47 US Department of Health and Human Services. Physical activity fundamental to preventing disease. US Department of Health and Human Services, 2002. http://www.aspe.hhs.gov/health/reports/physicalactivity (accessed 21 Nov 2004). 